\title{
Research on the Transformation of Scientific Research Achievements in Chinese Higher Education Institutes from the Perspective of Scientific Research Archives
}

\author{
SUN Yong-qing ${ }^{1, \mathbf{a}}$, ZUO Yang ${ }^{2, b}$ *
}

\author{
${ }^{1}$ Teaching Affairs Department of Shandong Technology and Business University, Yantai, Shandong, 264005, \\ ${ }^{2}$ Scientific Research Department of Shandong Technology and Business University, Yantai, Shandong, 2640005 \\ a157442812@qq.com \\ b*sdibtzy@163.com
}

\begin{abstract}
In recent years, with the rapid development of higher education in China, the scientific research environment of higher education institutes is superior with strong momentum. The scientific research achievements in a vast majority of higher education institutes have accelerated significantly. A large number of achievements have been successfully introduced to the market, which drives the economy to achieve effective growth. However, one thing that cannot be ignored is that although there is an increasing number of archives about scientific research achievements, the transformed achievements have remained at a relatively low level. Based on the perspective of scientific research archives, this paper systematically analyzes the problems and causes currently in the transformation of achievements in higher education institutes and then proposes the significance of quickening the establishment of a platform for the transformation of scientific research achievements in higher education institutes.
\end{abstract}

Keywords: Higher education institutes, scientific research archives, transformation of achievements, establishment of the platform.

\section{INTRODUCTION}

On May 28, 2021, General Secretary Xi Jinping made it clear in his speeches at the 20th Academician Conference of the Chinese Academy of Sciences, the 15th Academician Conference of the Chinese Academy of Engineering, and the 10th National Congress of the Chinese Association for Science and Technology: The new round of scientific and technological revolution and industrial transformation are advancing by leaps and bounds, the paradigm of scientific research is undergoing profound changes, the interdisciplinary integration continues to develop, and the penetration and integration of science and technology and economic and social development are accelerating. Scientific research, as one of the important indicators for the development of universities and the improvement of scientific research capabilities, makes universities an important position for the output of scientific research results and the research and development of innovative technologies, and has achieved fruitful results. The transformation of scientific research results of universities is the link that effectively connects enterprises and governments, is the main channel for universities to directly serve economic and social development, and is also an important manifestation of improving the core competitiveness of universities themselves. On October 17, 2020, the Standing Committee of the National People' s Congress passed the "Decision of the Standing Committee of the National People' s Congress on Amending the Patent Law of the People' s Republic of China” . At the same time, the Ministry of Education, the Ministry of Science and Technology, the Ministry of Finance and other relevant departments have successively made corresponding detailed regulations on the transformation of scientific research results of universities from the legislative level. However, the phenomenon of low conversion rate of scientific research results in colleges and universities still exists. After a large number of scientific research results enter the archives, they are put on the shelf and no one cares about them. Strengthening the transformation of scientific research results in 
universities is not only a requirement for promoting the orderly development of the scientific research environment and improving the level of scientific and technological progress, but also a necessary link for universities to promote connotation construction and actively build the process of integrating production, teaching and research. This article will start with the status quo of scientific research transformation in colleges and universities, clarify the reasons for the low transformation rate of scientific research achievements in colleges and universities, and then propose ways to accelerate the transformation of scientific research achievements in colleges and universities.

\section{STATUS QUO OF SCIENTIFIC RESEARCH TRANSFORMATION IN HIGHER EDUCATION INSTITUTES}

Due to the influence of policies, institutions and concepts, etc., scientific researches in higher education institutes have always been restricted by the concepts of focusing on achievements and research level while neglecting transformation and benefits. Behind the high yield of scientific research achievements is a low transformation rate. The study shows that $15 \%$ to $20 \%$ of scientific research achievements produced by higher education institutes each year are transformed into productivity, and only $5 \%$ of the achievements are industrialized with the patent implementation rate as merely about $30 \%$. Compared with up to $60 \%$ transformation rate of scientific research achievements in developed countries such as the United States, Japan and Britain, the effective transformation rate of achievements in scientific research institutions of Chinese higher education institutes is only about $10 \%$, while less than $5 \%$ of them are transformed into actual productivity. The transformation rate and speed of scientific research achievements in China are far lower than those in developed countries, causing a great waste of limited scientific and technological resources and reducing the rate of contribution to sci-tech progress. After completing the project review, a large number of scientific research achievements sent to the archives office are put on the shelf and nobody cares about them. This is undoubtedly a great waste of resources for countries with a low level of economic development and tight scientific research funding.

\section{ANALYSIS OF REASONS FOR LOW TRANSFORMATION RATE OF SCIENTIFIC RESEARCH ACHIEVEMENTS IN HIGHER EDUCATION INSTITUTES}

There are many reasons for the currently low transformation rate of scientific research achievements in higher education institutes. The author holds that the most important reasons can be summarized as follows:
3.1. The topic selection and approval of scientific research projects in higher education institutes don't keep pace with the need of the market, hence the achievements are difficult to be transformed due to a lack of practicability

"Topic selection is the primary step in the procedure of scientific research, and also a crucial factor to determine if scientific research achievements can be smoothly promoted or not. Only when the achievements cater to the market demand, there is a possibility of successful promotion." ${ }^{[1]}$ The market demand is a benchmark to measure if the scientific research achievements can be successfully transformed or not. To realize the effective transformation of achievements, we must follow the rules of the market in line with the market demand. Under the impact of the traditional model, most teachers in higher education institutes pay more attention to the academic value of scientific research achievements, particularly in professional title appraisal and social science awards, etc. with neglect of social value and economic effect of the achievements. This causes most scientific researchers to place more emphasis on the principle of achievements and advancement of structures in a topic selection of scientific research projects. Therefore, the objectivity required for transformation into actual productivity is ignored, resulting in more basic theory researches among a vast majority of achievements with fewer application-oriented researches, which is out of line with actual needs.

\subsection{An imperfect scientific research system and evaluation mechanism severely hinder the effective transformation of scientific research achievements}

"The transformation of scientific research achievements is a series of activities involving the fields of science, technology and economics, with many procedures and complex relationships. It is the movement process of scientific research achievements from the scientific research department to the production field." [2] The general scientific research achievements, after being produced, are still in the theoretical stage and are all samples, preliminary designs and models, etc. at the level of knowledge form. They cannot be directly applied to industrial and agricultural production. Research and demonstration must be conducted to improve the technological level and production efficiency and commercialize the achievements, which can truly transform them into effective productivity. This process calls for an establishment of effective communication, support, and cooperation channels between schools, enterprises and the government to ensure smooth transformation channels of achievements. However, the current scientific research system of higher education institutes is incomplete. Multiple effective cooperation channels 
cannot be established with enterprises and governments, which affects the extent to which the research achievements can be transformed.

\subsection{The innovative capability of scientific research archives management in higher education institutes is insufficient, which cannot adapt to the demand for transformation of achievements.}

"Scientific research archives of higher education institutes are rich in elements of technology, economy, intelligence and wealth. They are important intelligence knowledge for product development, technological innovation, scientific education, and research on the level of economic development in the region." [3] They not only record the entire process of scientific research activities in higher education institutes, but also record the creativity, methods and achievements of scientific researches in the scientific research process. They are the basis and reference index for scientific research activities, and complete, accurate and systematic materials of these activities from project approval to completion as well as significant information resources and valuable assets of the country. For the long term, the management of scientific research archives in higher education institutes lacks innovation and service awareness. In the aspect of archives management, the unfavorable phenomenon of merely focusing on collecting, organizing and preserving scientific archives while ignoring the effective development and utilization of these archives has been formed, which cannot meet the needs of achievements transformation.

\section{ANALYSIS OF THE PATH TO ACCELERATE THE TRANSFORMATION OF SCIENTIFIC RESEARCH ACHIEVEMENTS IN UNIVERSITIES BY TAKING MULTIPLE MEASURES}

Science and technology is the first productive force. "In the context of the era of knowledge-based economy, the transformation of scientific and technological achievements has become an important indicator of a country's sci-tech progress and the level of productivity." ${ }^{[4]}$ As a significant base for large producers with scientific research achievements, higher education institutes have become an important force in basic research and technological innovation. Scientific research staff in higher education institutes should maintain strong momentum in scientific research, and focus more on the transformation of achievements. Universities should also take multiple measures to further optimize the path for achievements transformation in higher education institutes and make the achievements obtained step out of the archives office into the market and society as soon as possible in a bid to better meet the needs of national economic construction and social development and progress.
4.1. We should be fully aware of the significance of scientific research achievements transformation in higher education institutes and attach great importance to the transformation of scientific research achievements.

In the current world, closer ties between the transformation of scientific research achievements and socio-economic development have been formed. The development of the core of science and technology is self-evident for socio-economic growth. "The core issue of scientific research lies in not merely a pursuit of the advanced scientific research achievements, but the commercialization, industrialization, and marketization of these achievements." ${ }^{[5]}$ As an important forward position of current scientific and technological innovation, higher education institutes must closely combine the actual changes with the needs of economic development. Administrators and scientific researchers must understand the significance of transformation and attach great importance to the transformation of scientific research achievements. We should enhance the work of achievements transformation to a height of strengthening the connotation construction of universities, improving the social influence and incorporating it into the long-term development planning strategy and various work of universities. The staff responsible for the management of scientific research archives should further enhance their awareness of innovative services, strengthen their connection with scientific researchers and make the scientific research archives stored in the archives office alive, leveraged and continue to play their part. We should further change the concepts, integrate scientific research achievements into the whole process of teaching, scientific research, management and personnel training as well as emphasize the cultivation of innovative talents. We should organize well and put into place the planning and construction of the achievements transformation, actively create a superior environment for the smooth transformation of such achievements and increase the transformation rate. 


\subsection{We should reform and deepen the scientific research system and establish a research evaluation index system that is scientific and reasonable.}

"Scientific research is conducted to publish thesis that is for professional title appraisal", which causes little attention to the application value, market development and promotion possibility of achievements. Therefore, a scientific research evaluation mechanism that is more objective, reasonable and effective must be established to actively guide scientific research evaluation, which not only puts unalterable indexes such as project size, number of papers and funding as scientific research evaluation factors, but also takes factors such as national demand, market needs, economic and social benefits into consideration for the unified assessment. In particular, we should further improve the scientific research reward mechanism to highlight incentives, promote the development and application of achievements by scientific researchers and should grant higher recognition and rewards to those making outstanding contributions to economic benefits. In this way, scientific research and achievements transformation can be integrated as a whole, which further enhances the transformation efficiency of achievements application and also forces scientific researchers to fully consider the feasibility and innovation of technological transformation in the approval of research projects. This is more conducive to the practicality and effectiveness of achievements with a value reflected in promoting economic development and preventing waste of human, materials and financial resources.

\subsection{The selection of research topics should highlight the market-oriented philosophy while changing the management concepts of scientific research archives.}

The market mechanism is the basis of economic development, and also the foundation of scientific and technological progress and the transformation of scientific research achievements. "The topic selection without application orientation makes a respectable part of scientific research achievements in Chinese higher education institutes deprived of potential practicality." [6] Strengthening the practicality of the scientific research process in higher education institutes from the beginning is the most important way to improve the transformation of achievements in Chinese higher education institutes. To avoid the possibility that many scientific research projects are unable to be transformed from the beginning, other types of scientific research projects and topic design should be established based on sufficient market demonstration and research besides basic research. The scientific research management department should strengthen management. For some projects with uncertain prospects or little application value of indirect achievements, they should not be approved or only allowed to be approved without financial support. For some technical research projects that are highly likely to be transformed or are currently in urgent need of production, adequate research guarantees should be given to effectively increase the possibility of their transformation. In addition, the management staff of scientific research archives must change their work concept promptly. They cannot only work for the preservation of archives but timely investigate and screen the materials stored in the archives office to fully exploit and leverage the current value of existing projects and promote them to the market as appropriate. They should actively keep the archives in pace with the market and production to maximize the role of research projects, which not only conserves resources, but also renews the vitality of projects.

\subsection{We should innovate the model of scientific research operation and embark on the path of integrating production-university-research development.}

There are many reasons for the unsatisfactory transformation of scientific research achievements in higher education institutes. For the scientific researchers themselves, most of them are teaching staff in higher education institutes, who don't go out of the campus into the grass-root unit at the frontier to acquire first-hand experience from original materials by encountering problems in production experience. Therefore, the establishment of many scientific research projects is at the stage of theoretical demonstration, which may cause them out of pace with social production needs and fail to solve practical problems by directly responding to the production needs. With the rapid development of society and changes in the knowledge production model, a new model of transformation of scientific research achievements has emerged, that is the so-called production-university-research model. Scientific researchers in higher education institutes should also follow closely and actively participate in this emerging model. They should innovate scientific research ideas, actively go out of the campus and walk into the enterprise and grassroots level. Through learning and practice in person, they will master technologies required by the enterprise, and then conduct effective researches, which can maximize the possibility in the transformation of scientific research achievements at the outset of the project approval, and lay a solid foundation for the application and promotion of the achievements.

Nowadays, the competition between sci-tech and talents has become increasingly fierce. The scientific researchers in higher education institutes undertake a glorious mission to train qualified socialist builders and successors. Hence, we should strengthen the guidance of 
scientific researches, shape our experience and consciously connect scientific research with the promotion of socio-economic development and improvement of national scientific and technological competitiveness. We should focus on actual needs, highlight market orientation, innovate scientific research operation models, optimize the management of scientific research archives and value the transformation and promotion of achievements in a bid to contribute self-worth to national scientific and technological progress and improvement of social productivity.

\section{CONCLUSION}

Receptive to the influence of factors such as regulatory mechanisms, management awareness, etc., compared with the production department of scientific research achievements, the level of scientific research achievements transformation in my country is relatively low. The specific reasons are that the topic selection is out of touch with the actual problems, the evaluation index system of scientific research results is not perfect, and the file management is not perfect. In order to enhance the scientific research transformation ability of universities and improve their contribution to the economic and social development of our country, we should attach great importance to the transformation of scientific research results in ideology, create a scientific and reasonable scientific research evaluation index system in terms of institutional mechanisms, and follow the problem-oriented approach in topic selection. At the same time, change the thinking of scientific research archives management in order to open up a multi-measured, integrated development path of government, industry, university and research.

\section{ABOUT THE AUTHOR:}

SUN Yong-qing, female, is a librarian. Her main research interest is archives management. Telephone: 15963594702. Address: No.191, Binhai Middle Road in Laishan District, Yantai, Shandong Province.

\section{REFERENCES}

[1] Zhang Xuexiang. Analysis on problems and countermeasures for the transformation of scientific research achievements in colleges and universities to start from scientific research archives[J]. Minzu Tribune, 2009(3):35-36.

[2] Xing Zongxin. Discussion on the transformation problems of scientific research achievements in colleges and universities[J]. Heilongjiang Researches on Higher Education, 1997(3):52-54.
[3] $\mathrm{Xu}$ Yurong. Exploration on the management of scientific research archives in colleges and universities[J]. Journal of Fuzhou University (Philosophy and Social Science), 2008(2):108-109.

[4] Zhang Meishu, Wu Jie. Outline of reasons and selection of countermeasures for low transformation rate of scientific research achievements in Chinese colleges and universities[J]. Journal of Jiangxi Finance College, 2008,21(1):109-111.

[5] Fan Lishuang. Analysis of problems and countermeasures for the transformation of scientific research achievements in colleges and universities[J]. China Higher Education, 2007(3):54-56.

[6] Xu Guoxing. Analysis of status, problems and countermeasures for the transformation of scientific research achievements in Chinese colleges and universities[J]. Higher Education of Sciences, 2013(6):27-33. 